\title{
GPR studies over the tsunami affected Karaikal beach, Tamil Nadu, south India
}

\author{
V J Loveson ${ }^{1, *}$, A R Gujar ${ }^{2}$, R Barnwal ${ }^{3}$, Richa Khare ${ }^{1}$ and G V Rajamanickam ${ }^{4}$ \\ ${ }^{1}$ CSIR-Central Institute of Mining and Fuel Research, Dhanbad 826 001, India. \\ ${ }^{2}$ CSIR-National Institute of Oceanography, Dona Paula, Goa 403 004, India. \\ ${ }^{3}$ CSIR-Central Mechanical Engineering Research Institute, Durgapur, India. \\ ${ }^{4}$ SASTRA Deemed University, Thanjavur, India. \\ *Corresponding author.e-mail: vjloveson@yahoo.co.uk
}

In this study, results of GPR profiling related to mapping of subsurface sedimentary layers at tsunami affected Karaikal beach are presented. A $400 \mathrm{MHz}$ antenna was used for profiling along $262 \mathrm{~m}$ stretch of transect from beach to backshore areas with penetration of about $2.0 \mathrm{~m}$ depth (50 ns two-way travel time). The velocity analysis was carried out to estimate the depth information along the GPR profile. Based on the significant changes in the reflection amplitude, three different zones are marked and the upper zone is noticed with less moisture compared to other two (saturated) zones. The water table is noticed to vary from 0.5 to $0.75 \mathrm{~m}$ depth (12-15 ns) as moving away from the coastline. Buried erosional surface is observed at $1.5 \mathrm{~m}$ depth (40-42 ns), which represents the limit up to which the extreme event acted upon. In other words, it is the depth to which the tsunami sediments have been piled up to about $1.5 \mathrm{~m}$ thickness. Three field test pits were made along the transect and sedimentary sequences were recorded. The sand layers, especially, heavy mineral layers, recorded in the test pits indicate a positive correlation with the amplitude and velocity changes in the GPR profile. Such interpretation seems to be difficult in the middle zone due to its water saturation condition. But it is fairly clear in the lower zone located just below the erosional surface where the strata is comparatively more compact. The inferences from the GPR profile thus provide a lucid insight to the subsurface sediment sequences of the tsunami sediments in the Karaikal beach.

\section{Introduction}

Mapping and modelling of the subsurface sedimentary layers on coastal beaches through conventional methods are always time consuming and challenging. Many conventional exploration methods, viz., trenching, shallow drilling by augers (vibrocorers, bunka drill or other drilling devices), geophysical methods (such as electric and gamma logs, shallow reflection seismic profiling, etc.) are already in use for investigation of the coastal sediments in shallow depth. All these methods of subsurface mapping have their own limitations on their utility. And now, the Ground Penetrating Radar (GPR) system, which is a nondestructive method, is proving to be the most suitable technique to study high-resolution subsurface stratigraphy (Maurya et al. 2005; Sridhar and Patidar 2005) including beach areas (Loveson et al. 2005; Devi et al. 2013).

A typical GPR system is essentially comprised of either a single transmitting and receiving antenna or two separate transmitting and receiving antennae, control unit, data logger, recording and

Keywords. GPR profiling; tsunami sediments; Karaikal beach; heavy mineral layers. 
display unit. The GPR technique works on the principle of reflection and refraction theory of electromagnetic waves. The reflection/refraction phenomenon is mainly governed by the electrical properties of the ground, i.e., the dielectric constant of the media is a measure of the ability of the material to allow the electromagnetic energy to propagate through it. Lower antenna frequencies are suitable for higher penetration, but do not give a good resolution. Resolution is approximately a quarter of the GPR wavelength, and ranges from $0.08 \mathrm{~m}$ for saturated sands with $200 \mathrm{MHz}$ antennae to $0.4 \mathrm{~m}$ for dry sands with $100 \mathrm{MHz}$ antenna.

The application of GPR, especially, in coastal studies is well known and is being widely employed in identifying and tracing various buried structures and facies in the beaches (Neal and Roberts 2000), dunes, bars, spits (Jol et al. 2002; Shukla et al. 2008) as well as in sand barriers (Meyers et al. 1994; Jol et al. 1996; Costas et al. 2006). Also, the GPR is used in modelling coastal aquifers (Makinen and Rasanen 2003), constructing coastal Pleistocene stratigraphy (Van Heteren et al. 1994; Daly et al. 2002) and studying the Pleistocene sealevel high stand sequences (O'Neal and McGeary 2002). A reconstruction of bed morphology of aeolian dunes has been attempted in southern Brazil (Da Silva and Scherer 2000) using GPR survey. Beach ridge sediments have been studied with 900 $\mathrm{MHz}$ antenna at northern Essex coastline, UK and it was found that there is good correlation with field data on the sets of lamination and beds (Neal et al. 2003). Storm dominated sediments in the barrier at the Castle Neck beach, USA have been mapped using $120 \mathrm{MHz}$ antenna where garnet layers were recorded at above $1 \mathrm{~m}$ depth (Dougherty et al. 2004). Sedimentary records of extreme events in Maine, USA have been correlated with GPR data and at least four storm scarps were identified (Buynevicha et al. 2004). With advancements in the GPR system and better understanding of GPR signals on geological materials, the use of GPR based subsurface surveys for high resolution profiling in the coastal areas has been increasing rapidly. An attempt has been made here in this study to map subsurface details, especially, the buried layering sequences in the tsunami affected beach along east coast of India.

\section{Regional setting}

Karaikal beach $\left(10^{\circ} 34^{\prime} \mathrm{N} ; 7^{\circ} 31^{\prime} \mathrm{E}\right)$, located in the central Tamil Nadu coast, India, was chosen for the present study (figure 1). The study area lies between Poompuhar and Nagapatinam coastal tract along central Tamil Nadu. The recent tsunami (24th December 2004) had transformed

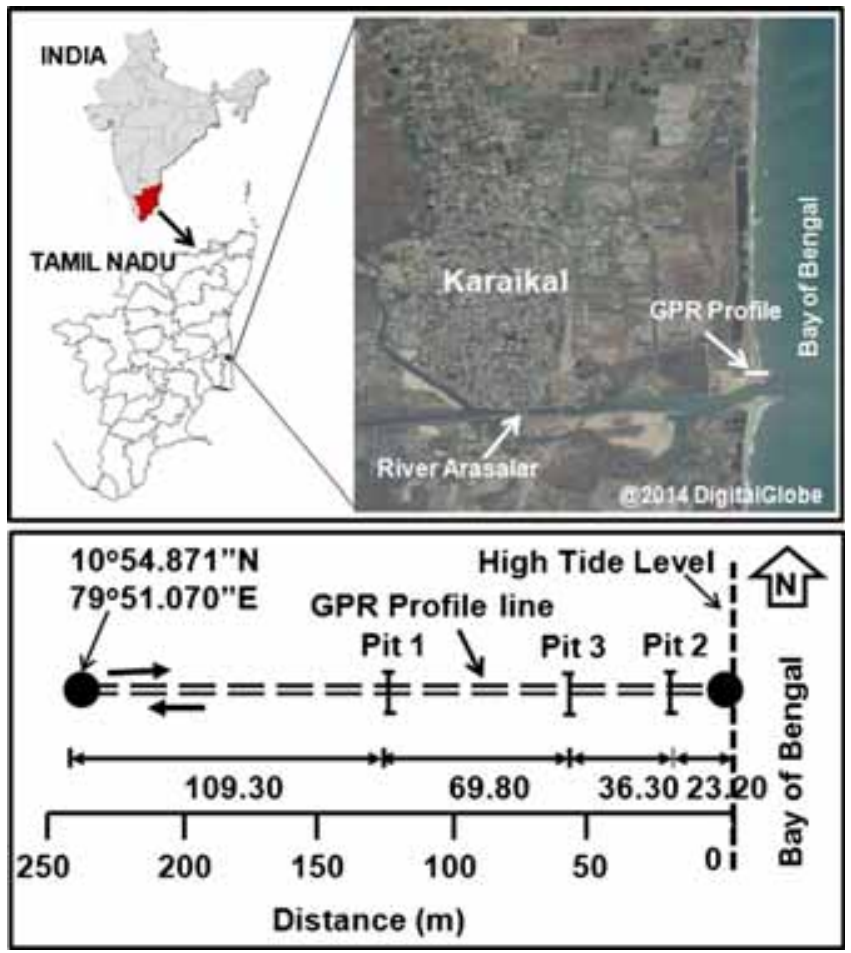

Figure 1. Location map of the study site with GPR survey plan.

the beach considerably with new sediments (Loveson et al. 2007, 2008).

The coastline is significantly straight, trending $\mathrm{N}-\mathrm{S}$ direction. The beach is moderately wide, having 500 to $700 \mathrm{~m}$ width with extensive backshore and gentle foreshore (figure 2). Well developed dune systems are observed in the backshore with limited vegetation on the crest of the dunes and are followed by low lying flat terrain towards landward. The backshore area is also represented by a thin, linear, but moderately elevated beach ridge. The beach has a moderate to steep slope. At the south, a small rain-fed Arasalar River joins the sea around this area which signifies a coastal lineament. Since the Karaikal beach is of an open sea type with a straight coastline configuration, the storms and extreme events directly influence the coast, causing appreciable damages to the coastal zone. During tsunami event of 2004, the entire geomorphological system was devastated and filled with new sediments. The present study was carried out to obtain subsurface information and also to possibly understand various reflector properties and amplitude changes related to different buried sand layers in the beach. Since 2003 (pretsunami period), studies related to beach morphological assessment and mineral characteristic evaluation were carried out in this area under the CSIR Network project. After the tsunami event (December 2004), it is found that the mineral and beach 



Figure 2. View of Karaikal shoreline (a) backshore and (b) foreshore areas.

characteristics have been significantly changed. In such a situation of sudden change, through this study, GPR has been used to find out whether or not any new information could be obtained in subsurface sediment deposition in beach and backshore coastal areas. This present study particularly throws light on the erosional surface and the characteristics of the recent build up sediments resulting from the extreme event.

\section{GPR Surveys}

Multi-frequency antennae (200 and $400 \mathrm{MHz}$ ) were used with a GPR SIR-20 system from GSSI (USA). A transect, perpendicular to the coastline, nearly $262 \mathrm{~m}$ long has been profiled with a 400 $\mathrm{MHz}$ antenna, covering the foreshore and backshore areas, traversing along the dunes (figure 1). Profiling has been repeated many times to compare and maintain the data quality in order to avoid possible errors due to antenna handling during field tracking. Similarly, a $200 \mathrm{MHz}$ antenna has also been put to use along the same transect to obtain time domain profile for comparing results with the other one. However, the profile obtained using $400 \mathrm{MHz}$ antenna is discussed in this paper due to its data clarity compared to the other one. In addition, along three test pits (P1, P2, and P3), many short GPR profiles were generated (parallel to the coast, i.e., N-S direction) using a $400 \mathrm{MHz}$ antenna, keeping the same GPR parameters (discussed below) as that of the main profile during field survey. These profiles were used for correlation with sediment logs obtained from the respective field test pits. Before GPR survey, the system was tuned to field conditions by settingup relevant parameters (gain, dielectric constant, scan scale, filters setting, etc.) and validating the measuring wheel for getting correct horizontal measurements. Marker was kept ready for appropriate use, if needed. Antenna was towed at optimum speed to register signals in the field computer. Survey was repeated a few times along the same pre-defined transect for consistency checking. The data thus obtained was processed in the laboratory with RADAN (5.0) software. The time domain GPR data were normalized with distance parameter and vertical scale adjustments to achieve a correct zero position for scaling. High frequency noise (snow) was removed with low pass filtering. High pass filtering was used to eliminate flat-lying ringing system noise. The deconvolution process was carried out to get rid of ringing multiples. The migration process was employed to remove diffraction (to compress hyperbolas) and to correct dipping layers. The digitally processed time domain GPR data thus was enhanced and viewed through linescan, oscilloscope and wiggle modes. Using these techniques (Anon 2003), the data quality was improved and interpretations were made accordingly. Besides, velocity analysis was also carried out for estimation of depth of various sand layers based on amplitude crosscorrelation method.

Beach profiles were generated along the GPR transect using Theodolite survey during pre- and post-tsunami period to understand the changes in the profiles due to deposition or erosion. Also, the bulk sediment sampling has been done at the high tide level to quantify the concentration of various sand minerals during pre- and post-tsunami period.

Along the GPR transect, three test pits were made (0.5-1.0 m depth) for correlation purpose so as to compare signatures of GPR reflectors with insitu layer information. In addition, sand samples were collected at selected depths in each test pit to record the mineral composition. 


\section{Results}

\subsection{Textural characteristics}

Samples were collected from low tide and high tide locations during pre- (one week before the tsunami event under regular fortnight sample collection exercise for mineral assessment program) and posttsunami periods (10 days after the tsunami event). From textural characteristics of the pre- and posttsunami sediments, the act of tsunami has been well documented (Loveson et al. 2007). There was a characteristic shift in pre- and post-tsunami sediments which has been significantly illustrated by the granulometric parameters of the sediments (figure 3). Based on the beach profiles generated during pre- and post-tsunami periods, Loveson et al. (2008) have indicated strong beach erosion followed by heavy sedimentation during the extreme event. The grain size parameters indicated a clear swing in values. Finer sands (pre-tsunami) were replaced by medium sands (post-tsunami). The mean values of the sediments of both high tide and low tide increased in post-tsunami scenario, thus indicating the deposition of coarser (medium) fractions of sediments. The post-tsunami sediments were poorly sorted. Based on the binary plots with respect to standard deviation versus skewness and mean versus skewness first movement to second movement, it is observed that pre- and post-tsunami sediments represent significantly different zones in the plots, indicating changes in the depositional environment (Loveson et al. 2007). As far as the energy level of deposition is considered, the high-tide samples of pretsunami showed their presence in the PQ sector denoting the dominance of rolling and suspension, whereas post-tsunami samples represented high energy turbulence zone of NOP, indicating the deposition in turbulence condition. Hence, the low tide and high tide, on the basis of CM pattern, reflect a strong diversity among sands of pre- and post-tsunami periods (Loveson et al. 2007).

\subsection{Sand mineral variation}

In consonance with the momentous geomorphological changes and granulometric variations, the sand mineral composition has also changed significantly after the extreme event in Karaikal beach. The light and non-opaque minerals, mainly, flaky mineral assemblages like chlorite, tremolite, biotite, glaucophane, etc., were completely washed away during erosion and the heavy mineral (HM) assemblages such as ilmenite and rutile were increased in double the portion by deposition thereafter during the extreme event. The concentrations of garnet and zircon were not modified significantly (Loveson et al. 2008). The heavy mineral concentration has risen from 28 wt\% (pre-tsunami sediments) to nearly $54 \mathrm{wt} \%$ after the tsunami. Enrichment is found to be more in the medium grain size fractions. The GSI (Geological Survey of India) studies on the post-tsunami sediments in Karaikal beach sediments had indicated the average HM of $61.46 \%$ (Anon 2006). Similar type of multi-fold increase in heavy mineral assemblages were also reported in nearby beaches (Loveson et al. 2008), indicating spells of erosion and redeposition during the extreme event. As expected, the magnitude of erosion and deposition varied from the tidal zone to backshore. Three test pits were made across the beach to backshore for getting more details on sequences of deposition. This


Figure 3. Grain size characteristics of inter-tidal sediments during pre- and post-tsunami periods. 
present study is focused on mapping the subsurface details for confirming the above-mentioned depositional phenomena in the post-tsunami period.

\subsection{Field observations at field test pits}

Along the profiling tract, three test pits were made in the beach and backshore areas for field observation. The pits 1,2 , and 3 are located at 130 , 23 , and $60 \mathrm{~m}$ respectively from the high tide level (figure 1). During trenching, the water level was usually met at $0.5-0.75 \mathrm{~m}$ depth. The disposition of various sand layers as observed in these pits is depicted in figure 4. Layers of white sand are observed at various depths with varying thickness. There are three white sand layers recorded in pits 1 and 2 of various thicknesses with alternative layers of heavy minerals. The bottom two heavy mineral layers (in pits 2 and 3 ) are variegating in nature with many thin laminae of white sand layers. The garnetiferous layer is uniformly similar (about 10 mm thickness) in all pits.

While analyzing the pattern of layers in these three pits (figure 4), one can infer that there were four stages of deposition within $50 \mathrm{~cm}$ depth during the tsunami. Leaving the top layer of loose black sand, the other bottom layers (below $25 \mathrm{~cm}$ ) deposited under the influence of the swirling erosion of earlier deposits representing high energy filled-in deposits.

The garnetiferous and above sand layers represent a comparatively less energetic scenario than earlier two beds, signifying the thrown away deposits. Because of the retrieval of waves at every stage, heavy minerals were left out in the backshore areas but light minerals were taken back due to their lesser density factor. This has been clearly represented in pits 3 and 2 situated near to the coast. Observations in pit 1 showed that the intervening white sand layers are thin, indicating more swirling activity between pits 1 and 2 location. Keeping the reference of interlining white sand layers, the above inference depicts that there were a few stages of deposition within $0.5 \mathrm{~m}$ depth. All these depositional activities further indicate the processes at the rear end of the tsunami event, representing the closing stage of high energy situations of the extreme event.

A short profile was generated along test pit 1 using a $400 \mathrm{MHz}$ antenna. Details of the pit are presented in figure 5 . The disposition and pattern of various sand layers are illustrated in figure 5(a) and the sediment log is shown in figure 5(b). For correlation purpose with these above field information, corresponding wiggle diagram (figure 5c) and velocity diagram are presented (figure $5 \mathrm{~d}$ ). The prime purpose of this comparison was to see whether there is any correlation that could be obtained from GPR data. The dominant reflections are observed with reference to heavy mineral layers and could be comparable with sediment log. Prominent change in velocity is noticed at $7.0 \mathrm{~ns}$ (25 cm depth), $8.5 \mathrm{~ns}$ (35 cm depth) in the velocity diagram, indicating different layer composition. This is comparable again with heavy mineral layers in the sediment log.

Similar profiling and analysis were carried out for test pit 3 as well and compared with its field $\log$ (figure $6 \mathrm{a}, \mathrm{b}, \mathrm{c}$ and $\mathrm{b}$ ). The nature of

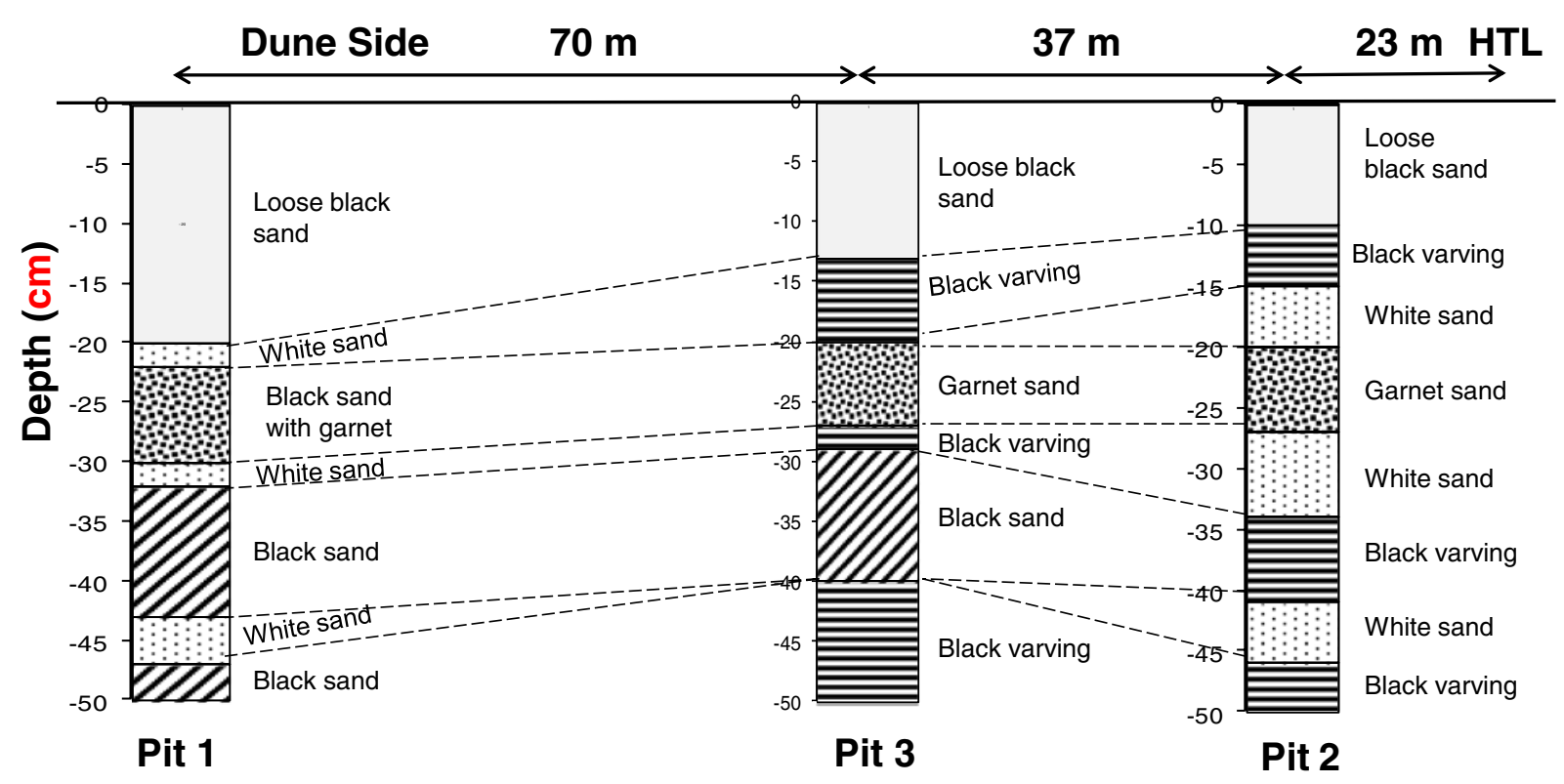

Figure 4. Comparison of various sand layer sequences from field test pits. 


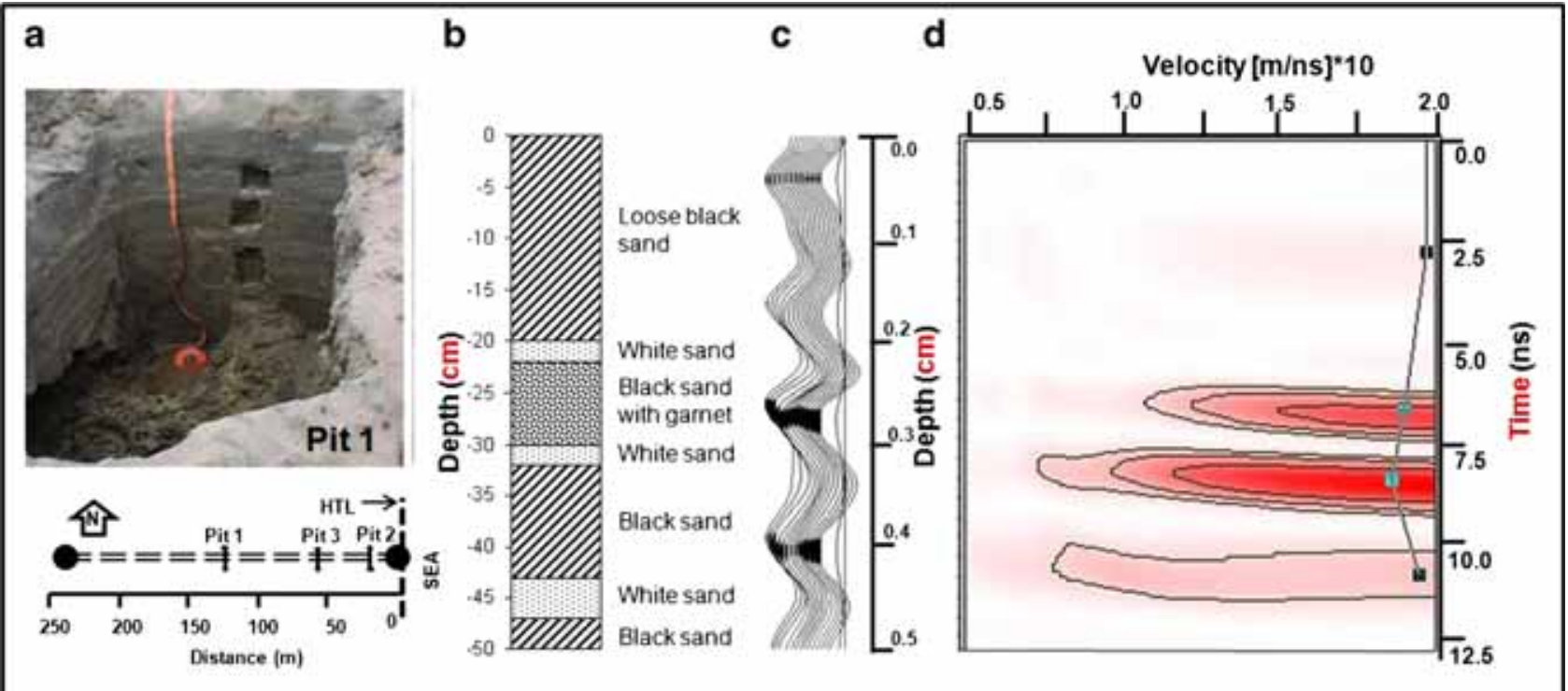

Figure 5. Correlation of field information with GPR details (400 MHz antenna) around test pit 1. (a) Sand layers observed in the pit, (b) sediment log, (c) wiggle traces and (d) velocity diagram.

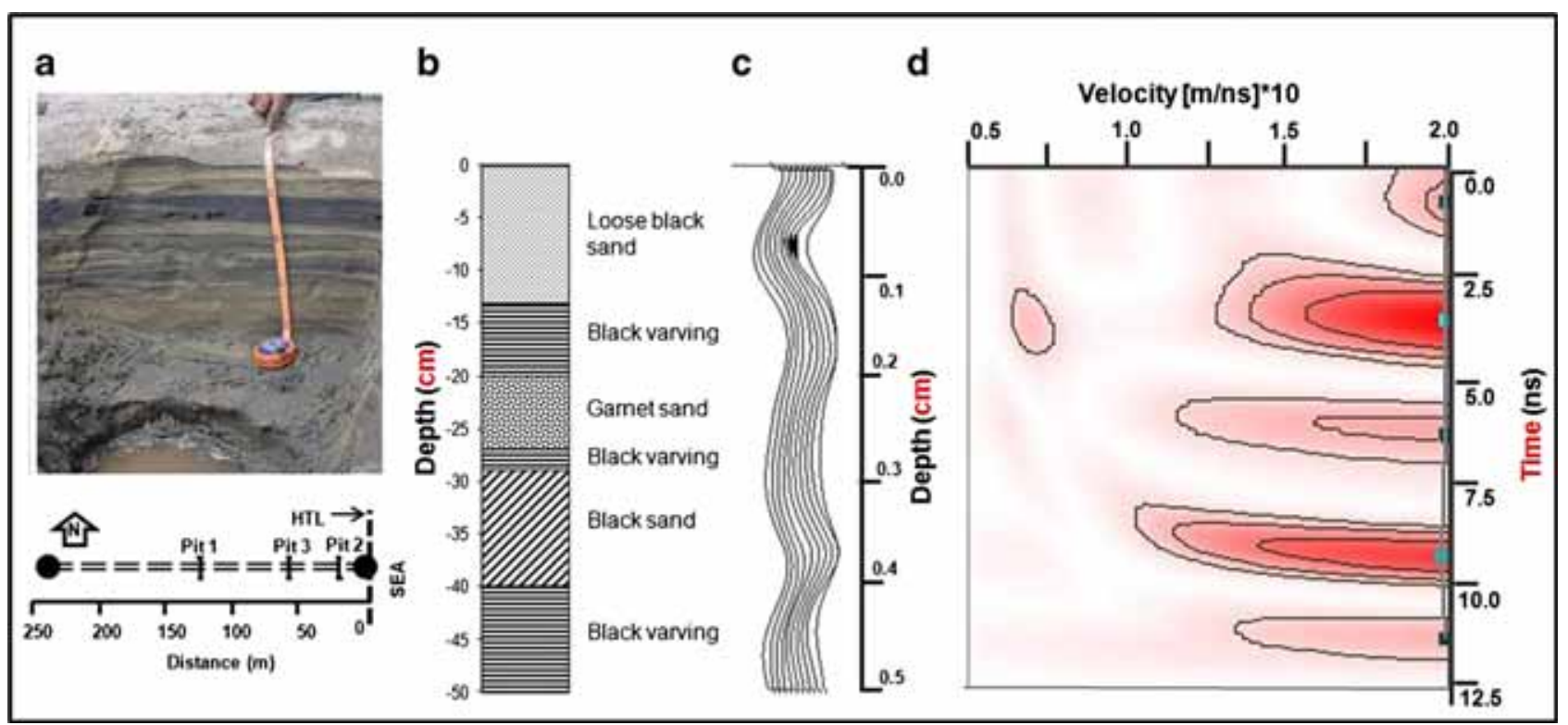

Figure 6. Correlation of field information with GPR details (400 MHz antenna) around test pit 3. (a) Sand layers observed in the pit, (b) sediment log, (c) wiggle traces and (d) velocity diagram.

wiggle straightness infers more water saturation which may be due to its location near buried paleo runnel feature. Though more information could not be extracted from the wiggle traces due to high moisture level, the velocity diagram provides convincing information on velocity changes with respect to each heavy mineral layer. It is observed that velocity significantly changes at 3.5 ns (0.15 m depth), $6.0 \mathrm{~ns}$ (25 cm depth), and 9.0 ns (37 cm depth). These values could be compared with heavy mineral layers. These comparisons could lead to convincing results on lithological correlation with GPR data (within $50 \mathrm{~cm}$ depth) and also initiate more detailed approaches in this field.

Along pit 2, one can notice from the sediment log that the heavy mineral layers and white sand layers are alternatively sequenced, having almost equal thickness of about $10-12 \mathrm{~cm}$ each. There are four distinctive heavy mineral layers (figure $7 \mathrm{a}$ and b) observed from the test pit. The wiggle traces are simple (figure $7 \mathrm{c}$ ) and it is difficult to infer anything related to layer sequence. But the velocity diagram (figure $7 \mathrm{~d}$ ) spells out layer 


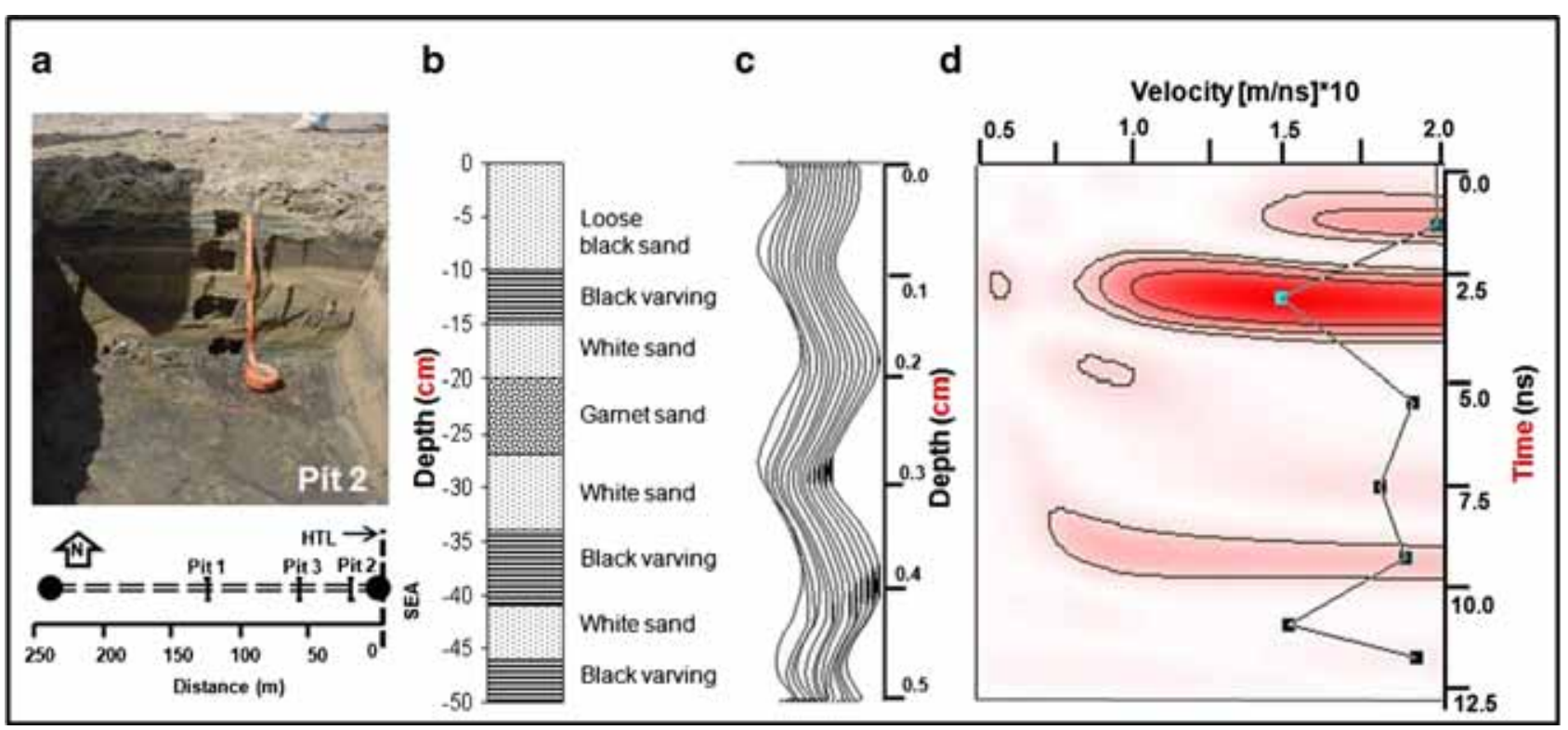

Figure 7. Correlation of field information with GPR details (400 MHz antenna) around the pit 2. (a) Sand layers observed in the pit, (b) sediment log, (c) wiggle traces and (d) velocity diagram.

information comprehensively, by way of velocity changes. Significant velocity changes are observed at 2.5-3.5 ns (10-15 cm depth), and 9.0-10.0 ns (35-40 cm depth) which have positive correlation with black sand layers. But, the garnet layer at 5.0-6.5 ns (20-25 cm depth) indicates less velocity values compared to other black sand layers due to its coarse grain nature, more saturation and more porosity.

Above interpretations have demonstrated the comparability of GPR subsurface information with field log details related to various pits. In other words, based on the radar reflection, velocity change and amplitude variance, various layer sequences and their characteristics could be brought out considerably with the GPR data. With this background, a longer profile, with greater depth of Karaikal beach was interpreted in detail after velocity analysis and is discussed below.

\subsection{Velocity analysis}

If the propagation velocity is measured, then the absolute of depth or thickness can be derived. In case of homogeneous and isotropic media, the relative propagation of velocity is calculated from $v r=c / \sqrt{ } \varepsilon r \mathrm{~ms}^{-1}$ and the depth is derived from $d=v r \frac{t}{2} \mathrm{~m}$; where $\varepsilon r$ is the relative permeability and $t$ is the two-way time from the target (Daniels 2007).

The velocity analysis is generally performed to estimate depth from two-way travel time, given with electrical properties of the media. The time domain data, generated through GPR, were recorded in 2-way travel time format in nano-seconds (ns) with reference to di-electrical constants of the subsurface media as well as the gain setting in the system. In the present study, the velocity analysis (figure 8) was carried out to estimate the depth to various layers on the GPR data obtained from a $400 \mathrm{MHz}$ antenna. A good velocity model is basically based on stacking (improvement in signal-to-noise ratio), appropriate conversion from travel time into depth, and migration (spatial corrections) procedures. Among different ways to measure the velocity, the analysis of velocity spectra is one which is being widely used by the software.

The method, adopted here, is based on computing the velocity spectrum. The cross correlation method was used, which generates less scatter in the data analysis. The velocity spectrum is achieved when stacking results are plotted with velocity ( $\mathrm{x}$-axis) versus two-way travel-time ( $\mathrm{y}$ axis) as iso-amplitudes. Using highest amplitude in each elliptical area with iso-line function, the velocity contours were drawn from which each layer is defined. With reference to the main profile obtained from a $400 \mathrm{MHz}$ antenna, the velocity diagram shows three significant zones (figure 8a and b) bounded by two reflectors at around 20 and 40 ns. The velocity diagram indicates that the two bottom zones (middle and lower zones) have a defined velocity range (true velocity of 0.25 and $1.62[\mathrm{~m} / \mathrm{ns}] * 10$ respectively). But the upper zone indicated mixed true velocities which indicate/suggest the possibilities of either mixed sand materials or varying moisture levels within. The latter reason was found to be true 



Figure 8. (a) Time domain wiggle diagram depicting the characteristics of vertical GPR amplitude traces (on a $400 \mathrm{MHz}$ antenna); and (b) velocity diagram and layer information window of the same profile.

as the field test pits indicated water saturation from below $0.5 \mathrm{~m}$ depth and comparatively dryness above $0.5 \mathrm{~m}$ depth. Thus, sudden disappearance of signal strength below $0.5 \mathrm{~m}$ indicates the water saturation line (water table), which was illustrated in the velocity diagram significantly. Apart from the upper zone, the other two bottom zones were significantly illustrated based on velocity parameter along with remarkable water table at $0.5 \mathrm{~m}$.

\subsection{Main GPR profile and interpretation}

Keeping the light house at the Karaikal beach as a reference point, a transect of about $262 \mathrm{~m}$ length, perpendicular to the coastline, was profiled up to the high tide level (HTL). The SIR-20 GPR system from GSSI (USA) was used during the surveys with a $400 \mathrm{MHz}$ antenna. The acquisition time was set, so that the penetration would be about $2 \mathrm{~m}$ depth. In addition, a $200 \mathrm{MHz}$ antenna was also used along the same transect for correlation purposes.

The subsurface profile up to HTL is presented in the closely spaced wiggle format in figure 8(a). The fill level of the polarity of positive and negative pulses has been kept at $50 \%$ for better visualization. Based on velocity analysis, depth has been computed. There are three significant zones observed with varying characters of vertical wiggle traces as far as the amplitude is concerned in the GPR signal. Based on the velocity diagram and the reflectors, change in reflection amplitudes and velocity (figure 8b) are observed at 20-22 and 40-42 ns which equals to 0.75 and $1.65 \mathrm{~m}$ depth. These changes signify three zones vertically. The upper zone (UZ) is up to $20 \mathrm{~ns}$ (0.75 $\mathrm{m}$ depth) indicating dry nature of the sandy layer. Higher amplitude values are recorded from starting point of the profile $(0 \mathrm{~m})$, to $165 \mathrm{~m}$ length. But, amplitude decreases towards seaside, revealing increase in moisture level. This nature has been confirmed by the field observations through test pits. The water table appears at about 12 to $15 \mathrm{~ns}(0.50-0.75$ $\mathrm{m})$ which have also been substantiated by the evidence from the pits. It is also noticed that within the upper zone, the reflection amplitude is weaker in the near-surface (i.e., up to $0.25 \mathrm{~m}$ depth) area. This indicates the nature of surface moisture.

The middle zone (MZ), representing 20-40 ns (0.75-1.50 m depth) has shown featureless wiggle traces with less reflection amplitude (figure 8a). With weak signals and less amplitude, the MZ indicates water saturation condition. In the field pits, we could not dig below $0.5 \mathrm{~m}$ due to water table condition. In spite of weak amplitudes in this zone, the waviness of wiggle traces in some areas indicates different thin sand layers within (at least six minor layers) as observed in figures 8 and 9 . However, the velocity diagram distinguishes this zone from other zones by way of indicating different velocity values (figure $8 \mathrm{~b}$ ). Three locations (horizontally 30-40 m; 165-175 $\mathrm{m}$ and 205-215 m) (figures 8 and 9) having very weak amplitudes are observed in the MZ. These could be representing runnels (RL), which run parallel to the coast. These runnels might be small swales but filled with water and connected with the nearby river (Arasalar?) or sea through other means of drainage channels.

The lower zone (LZ), which starts from 42 ns (1.5 $\mathrm{m}$ depth) and beyond down, is represented by higher amplitude signals (figure 9). Though the lower zone is saturated with water, the compactness of the strata might have been one of the reasons that characterizes the signals with 


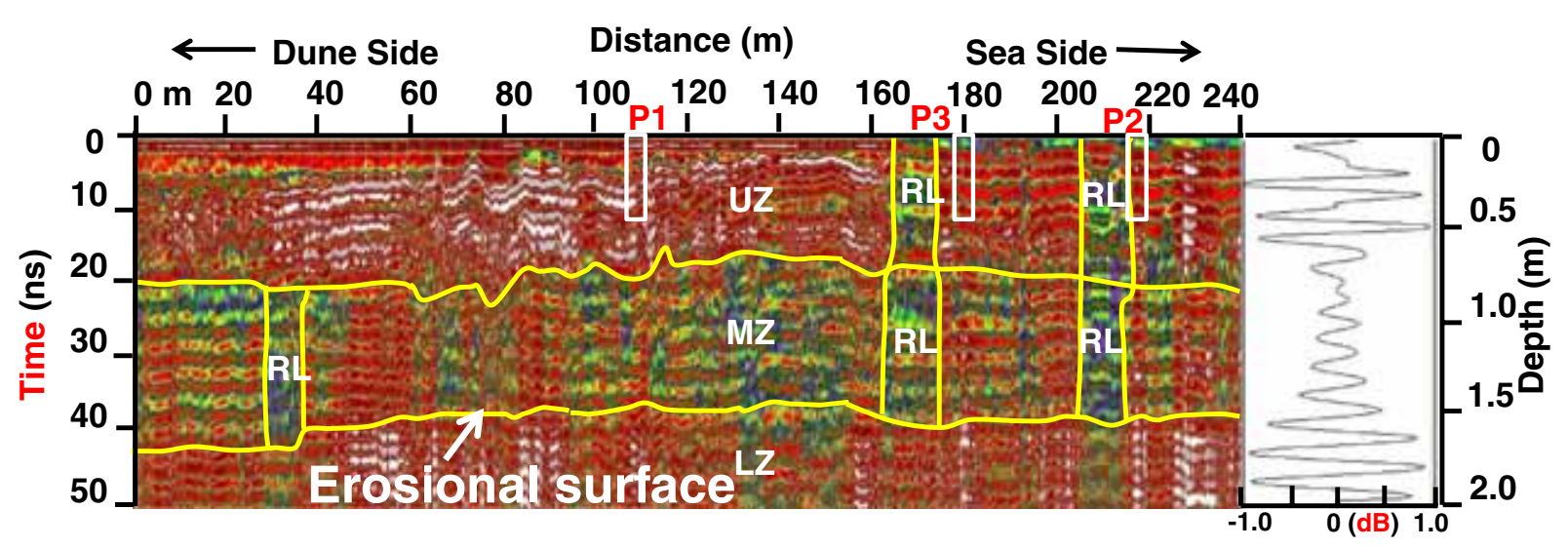

Figure 9. Time domain GPR data (400 MHz) and interpretation of various zones and other buried features (UZ: Upper Zone; MZ: Middle Zone; LZ: Lower Zone; RL: Runnel; P1, P2 and P3: Field pits).

higher amplitude. The higher values of amplitude indicate the consolidated nature of the sand layers which could be considered as an unaffected and remnant zone. Generally, considerable attenuation in signals would be observed with increase in depth, especially in coastal zone due to saline moisture saturation. But here, after the poor amplitude nature observed in the MZ, the down below LZ shows remarkably higher amplitude values (figures 8 and 9), indicating the compactness of the sediments in LZ which is duly attested by the significant changes in the amplitude and velocity in both zones. Due to water saturation condition below $0.5 \mathrm{~m}$ depth onwards during trenching and augering in the field works, it was not possible to get samples up to $1.5 \mathrm{~m}$ depth to confirm this character. But the GPR profile clearly portrays changes in the character based on the reflectance as well as velocity in each zone identified. On this account, LZ could possibly be a relict zone (undisturbed by tsunami action) and the boundary thus marks the erosional character on which the recent tsunami sediments were deposited. This erosional boundary feature between MZ and LZ is clearly traceable and is irregular but maintains in the level of 40-42 ns range (1.5 $\mathrm{m}$ depth) (figures 8 and 9). The nature of the irregular boundary infers the possible partial signature of earlier dune system and ridges which were washed away, during the recent tsunami deposition. From the above observations, the UZ and the MZ could be major spells of depositions either in two stages or in a single one, having been provided with many thin layers. The boundary between UZ and MZ is more irregular than the bottom one, indicating more micro-swirling effects in the middle of the profile. The MZ is fully saturated with water, due to the hydrodynamics with the sea water intrusion. These observations on nature of water saturation in all three zones are substantiated appropriately by a single wiggle trace which is presented along the main profile (figure 9). Since the GPR data was improved with low pass filtering process, the high frequency noise (snow) was removed and the high pass filtering was used to eliminate flat-lying ringing system noise. Subsequently, the ringing multiples and diffractions (hyperbolas) were also eliminated through deconvolution and migration processes. In these processes, the noise factor was suppressed and interpretations were done accordingly.

\section{Discussions}

Based on distinctiveness in separation of these three zones by way of signal characteristics, velocity changes, and amplitude variance, it could be summarized that $1.5 \mathrm{~m}$ depth level indicates the buried erosional surface over which tsunami sediments were deposited. In other words, during tsunami event, the top portion of the beach was eroded and removed by the force of continuous wave action and subsequently nearly $1.5 \mathrm{~m}$ thickness of sand material was re-deposited. Through the buried runnels, the left-out water was partially drained out until those runnels were subsequently filled-up by sediments. Heavy minerals dominantly represented the newly deposited sediments. The laboratory analysis on bulk surface samples shows that the concentration of the heavy minerals has increased from 28 to $54 \%$ respectively during pre- and post-tsunami events (Angusamy et al. 2005). Moreover, earlier studies showed that the sediment characteristics changed significantly in view of deposition by the extreme events (Loveson et al. 2007). This situation is also comparable to the observations made in some coastal barriers in the USA (Buynevicha et al. 2004; Dougherty et al. 2004). 
From the test pits, the higher heavy mineral concentration was noticed towards backshore areas up to $1 \mathrm{~m}$ depth. Due to higher force of waves, the heavy minerals with high specific gravity have been thrown inland and subsequently, the lighter minerals might have been panned out in different stages of wave action during the extreme event. This has been remarkably observed through test pits as lighter mineral concentrations are found to be more at sea side, gradually decreasing towards dune side. Below the buried erosional surface, sand strata was more compact, compared to middle and upper zones. It could be presumed that the sand layers above buried erosional surface which represent the tsunami sediments, are less compact and saturated with water up to $0.75 \mathrm{~m}$ depth.

Various sand layers are significantly observed in the test pits. The short profiles along test pits, recorded with a $400 \mathrm{MHz}$ antenna, confirmed the disposition of various layers in correspondence with the sediment log. There are four prominent heavy mineral sand layers up to $0.5 \mathrm{~m}$ depth from the surface (figure 4), provided with varying concentration and composition. The wiggle and velocity diagrams established a positive correlation with field information. The velocity changes are comparable with various sand mineral layers. Moreover, top surface layer represents loose sand intermixed with white and heavy minerals. It is observed that the vertical wiggle traces with higher or lesser amplitudes respectively indicate the dry or the moisture/saturation situation.

The field inspection from bulk sample analysis shows that the surface layer $(0.25 \mathrm{~m}$ depth) is richer in heavy mineral concentration up to $160 \mathrm{~m}$ stretch horizontally and comparatively lesser from $160 \mathrm{~m}$ to the HTL. The above observation is substantiated by the GPR interpretation (figure 9) where it is noticed that the heavy mineral concentration increases from 40 to $160 \mathrm{~m}$ stretch and from 230 to $240 \mathrm{~m}$ stretch of the profile in upper zone. This can be noticed in the profile by way of high reflection amplitude sand layers. Likewise, the lower zone has indicated similar situations at $50-110 \mathrm{~m}$ and 220-250 m subsurface areas (below $1.5 \mathrm{~m}$ depth). Though it could not be confirmed from the field data in this study, the reality could be established by taking the example of the upper zone situation.

Figures 8 and 9 indicate that the reflection amplitude strength in MZ is comparatively lesser than other zones. This signal attenuation in MZ may be due to high moisture/saturation condition. It is to be noted that water table appears at 0.5 to $0.75 \mathrm{~m}$ depth level. One can also observe the runnel features in UZ and MZ (figure 9). Significantly three runnels were seen in the MZ while there were traces of these runnels in the LZ as well. Also, some runnels were observed as a continuation in the UZ also. This clearly indicated that even after the deposition by extreme event, the coastal processes got renewed with their usual and typical activities with reference to this particular coast.

\section{Conclusions}

In this study, the GPR profiles were used to understand the subsurface details of the Karaikal beach up to $2 \mathrm{~m}$ depth after the tsunami event of 2004. The present study has led to the following conclusions:

- Based on the reflectors and amplitude characteristics, three zones are observed up to 2.0 $\mathrm{m}$ depth. The upper zone comparatively shows lesser moisture and signals are clear with higher amplitude.

- The water table is noticed at $0.5-0.75 \mathrm{~m}$ depth, moving away from the coastline to dune area. The lower and middle zones are saturated with water. Since the lower zone is comparatively more compact than the middle zone, the signals are better than the latter one.

- The buried erosional surface is observed at $1.5 \mathrm{~m}$ depth after which the strata is more compact.

- The mineral sand layers which are recorded in the field pits have fairly good correlation with high resolution GPR data. The correlation is also achieved through the velocity and wiggles analyses.

- Keeping these correlations, it has been observed that the heavy mineral concentration is indicated in the upper zone from 40 to $160 \mathrm{~m}$ stretch length of the profile. Such interpretation seems to be difficult in the middle zone due to its water saturation condition, but it is fairly clear in the bottom zone located just below the erosional surface, which appears at $1.5 \mathrm{~m}$ depth.

- The buried erosional surface indicates that the tsunami sediments have been piled up to $1.5 \mathrm{~m}$ thickness.

- The presence of buried runnel features in all three zones indicates the rehabilitated characteristic action of coastal zone dynamics even after the extreme event as signatures of these runnels are traced in all the three zones as continuous features.

\section{Acknowledgements}

The financial supports from the Paleo-tsunami project (MoES) and CSIR Network Project (CMM 23) are thankfully acknowledged. The authors wish to thank the Directors of CIMFR and NIO and Vice-Chancellor of the SASTRA University for permission to publish this paper. They thank 
Dr A K Chaubey, Associate Editor of the journal for his coordination and support extended throughout the review process. Authors are thankful to the reviewers for their constructive comments and useful suggestions to improve the quality of the paper. Thanks are due to the department as well as all field staff for their cooperation and support during field works and the laboratory analysis.

\section{References}

Angusamy N, Manickaraj D S, Chandrasekar R, Chadrasekar N, Gujar A R and Rajamanickam G V 2005 Heavy mineral distribution in the Nagapatinam district, Tamil Nadu, India; In: Developmental Planning of Placer Minerals (eds) Loveson V J, Chandrasekar N and Sinha A (New Delhi: Allied Publ.), pp. 80-94.

Anon 2003 Radan for Windows, version 5.0, User Manual: Geophysical Survey Systems Inc., USA.

Anon 2006 Post-tsunami studies carried by Marine Wing of Geological Survey of India; In: Tsunami-A Geoscientific Perspective (ed.) Rajamanickam G V (New Delhi: New Academic Publishers), pp. 177-182.

Buynevicha I V, FitzGeralda D M and van Heteren S 2004 Sedimentary records of intense storms in Holocene barrier sequences, Maine, USA; Mar. Geol. 210 135-148.

Costas S, Alfjo I, Rial F, Lorenzo H and Nombela M A 2006 Cyclical evolution of a modern transgressive sand barrier in northwestern Spain elucidated by GPR and aerial photos; J. Sedim. Res. 76 1077-1092.

Daniels D J 2007 Ground Penetrating Radar; 2nd edn, The Institution of Engineering and Technology, London, United Kingdom, 24p.

Da Silva F G and Scherer C M D S 2000 Morphological characterization of ancient aeolian dunes using the groundpenetrating radar, Botucatu Formation, southern Brazil; Revista Brasileira de Geociências 30(3) 531-534.

Daly J, McGeary S and Krantz D E 2002 Groundpenetrating radar investigation of a late Holocene spit complex: Cape Henlopen, Delaware; J. Coast. Res. 18 $274-286$.

Devi K, Vijaya Lakshmi C S, Raicy M C, Srinivasan P, Murthy S G N, Hussain S M, Buynevich I and Nair R R 2013 Integrated approach of assessing sedimentary characteristics of onshore sand deposits on the Velankanni coast, Tamil Nadu, India: Sheds light on extreme wave event signatures; J. Coast Conserv. 17 167-178.

Dougherty A J, FitzGerald D M and Buynevich I V 2004 Evidences for storm-dominated early progradation of Castle Neck barrier, Massachusetts, USA; Mar. Geol. 210 123-134.

Jol H M, Lawton D C and Smith D G 2002 Ground penetrating radar: $2 \mathrm{D}$ and $3 \mathrm{D}$ subsurface imaging of a coastal barrier spit, Long Beach, WA, USA; Geomorphology 53 $165-181$.

Jol H M, Smith D G and Meyers R A 1996 Digital Ground Penetrating Radar (GPR): A new geophysical tool for coastal barrier research (examples from the
Atlantic, Gulf and Pacific coasts, USA); J. Coast. Res. 12 960-968.

Loveson V J, Barnwal R P, Singh V K, Gujar A R and Rajamanickam G V 2005 Application of ground penetrating radar in placer mineral exploration for mapping subsurface sand layers: A case study; In: Developmental Planning of Placer Minerals (eds) Loveson V J, Chandrasekar $\mathrm{N}$ and Sinha A (New Delhi: Allied Publ.), pp. 71-79.

Loveson V J, Chandrasekar N, Gujar A R, Rajamanickam G V, Manickaraj D S, Chadrasekar R, Chaturvedi S K, Josphine P, Deepa V, Sudha V and Sundaresan D 2007 Post-tsunami rebuilding of beaches and the texture of sediments; In: Exploration, Exploitation, Enrichment and Environment of Coastal Placer Minerals (eds) Loveson V J, Sen P K and Sinha A (New Delhi: MacMillan Publ.), pp. 131-149.

Loveson V J, Angusamy N, Gujar A R, Chandrasekar N and Rajamanicakm G V 2008 Observed inferences from sudden changes in the sedimentalogical processes during the December 2004 tsunami along the east coast of India; Science of Tsunami Hazards 27(4) 43-52.

Makinen J and Rasanen M 2003 Early Holocene regressive spit-platform and nearshore sedimentation on a glaciofluvial complex during the Yoldia Sea and the Ancylus Lake phases of the Baltic Basin, SW Finland; Sedim. Geol. 158 25-56.

Maurya D M, Patidar A K, Mulchandani N, Goyal B, Thakkar M G, Bhandari S, Vaid S I, Bhatt N P and Chamyal L S 2005 Need for initiating ground penetrating radar studies along active faults in India: An example from Kachchh; Curr. Sci. 88(2) 231-240.

Meyers R A, Smith D G, Jol H M and Hay M B 1994 Internal structure of Pacific Coast barrier spits using ground penetrating radar; Proc. Fifth Int. Conf. on GPR, pp. $843-854$.

Neal A, Richardsb J and Pyeb K 2003 Sedimentology of coarse-clastic beach-ridge deposits, Essex, southeast England; Sedim. Geol. 162 167-198.

Neal A and Roberts C L 2000 Application of groundpenetrating radar (GPR) to sedimentological, geomorphological and geoarchaeological studies in coastal environments in coastal and estuarine environments; In: Sedimentology, Geomorphology and Geoarchaeology (eds) Pye K and Allen J R L, Geol. Soc. London Spec. Publ. 175 139-171.

O'Neal M L and McGeary S 2002 Late Quaternary stratigraphy and sea-level history of the northern Delaware Bay margin, southern New Jersey, USA: A ground penetrating radar analysis of composite Quaternary coastal terraces; Quat. Sci. Rev. 21 929-946.

Sridhar A and Patidar A 2005 Ground penetrating radar studies of a point bar in the Mahi River basin, Gujarat; Curr. Sci. 89 183-189.

Shukla S B, Patidar A K and Bhatt N 2008 Application of GPR in the study of shallow subsurface sedimentary architecture of Modwa spit, Gulf of Kachchh; J. Earth. Syst. Sci. 117(1) 33-40.

Van Heteren S, FitzGerald D M and McKinlay $\mathrm{P} A$ 1994 Application of ground-penetrating radar in coastal stratigraphic studies; Proc. Fifth Int. Conf. on GPR, pp. 869-881. 